\title{
Research on Development Status and Strategies of Digital Publishing Industry
}

\author{
Du Wenfeng, Liu Baohui \\ Affiliated Hospital of Taishan Medical University, Shandong, Taian, 271000
}

Keywords: digital publishing industry; development status; development strategy; inquiry

\begin{abstract}
As time progressed, the development of the digital publishing industry is accelerating. The digital publishing industry is characterized by low cost, strong environmental protection, and convenience. The profit model is also diversified. However, the corresponding problems are equally numerous. For example, problems in copyright scramble often occur. Therefore, it is necessary to formulate corresponding development strategies according to the actual situation of the development of the digital publishing industry, and scientifically and reasonably strengthen the healthy progress of the digital publishing industry.

With the rapid development of science and technology nowadays, people's reading methods have also been changed to digital reading, and the digital publishing industry is also booming. The digital publishing model has many advantages, such as wider dissemination range, faster update speed, and lower cost. Therefore, digital publishing not only enriched and improved the content and form of publications, but also formed a mainstream form of publishing. The digital publishing is an emerging industry. The state and local governments have also paid high attention to it and have provided corresponding support in the policy.
\end{abstract}

\section{Status Quo of Digital Publishing Industry Development}

\subsection{A relatively relaxed development environment}

The rapid development of Internet information technology means that the publishing industry will continue to evolve in the direction of digitization, which will provide a relatively easy development environment for the digital publishing industry to a certain extent, mainly shown in the following aspects: Firstly, in terms of the political environment, the state has successively introduced a series of corresponding policies to support the development of the digital publishing industry, such as the "Planning" and "Mobile Media Publishing Service Management Measures" issued in 2011 and "Opinions" and "National Outline for Cultural Development during the Eleventh Five-Year Plan" issued in 2010 by GAPP. The introduction of these policies all shows that the state attaches great importance to the progress of the digital publishing industry. Secondly, in terms of the economic environment, China's economic development level has been continuously improved in recent years, the growth rate of national GDP has been continuously increased, and there with the per capita income of the people. The increasing economic strength of the country and the people has promoted the improvement of the consuming ability of digital publications in China and has also led to the continuous advance of the digital publishing industry, which has brought a closer connection between culture and digital technology. Such social environment provides good conditions for the development of the digital publishing industry ${ }^{[1]}$.

\subsection{Diversification of profit models and rapid development}

The main factors of the digital publishing industry include digital periodicals, online advertising, e-books, online game, mobile publishing, digital newspapers, and so on. With the development of the Internet, the developmentscope of the digital publishing industry is constantly expanding, and people's reading mode is becoming more and more diversified, which has, to a certain extent, prompted the continuous increase in the speed of digital progress. According to the display of private network data in recent years, the output of digital publishing is increasing very fast,which 
shows, to some extent, that the profit model of the digital publishing industry is diversified.

\section{Problems in the Development of Digital Publishing Industry}

In China, there are still some problems in the development of the digital publishing industry. The most common problem is infringement, mainly due to the emergence of copyright issues during the development of the digital publishing industry, resulting in many infringement disputes.Besides, there are no relevant provisions to clarify responsibility for the infringement, and it is difficult to obtain evidence. Cost for safeguarding rights is also high, and the awareness of both parties in this aspect is also relatively weak. At the same time, China has not yet concretely improved the laws and regulations governing digital publishing copyright authorization. Therefore, the author's own legitimate rights and interests are not adequately protected. Whether it is just an e-book, a scientific paper, or an original literary work, as long as it is a publishing business, it will face copyright issues. In addition, although the digital publishing industry is developing at a very fast pace, its level of development is uneven, its development goals are inconsistent, and there are no corresponding and relevant regulations on the copyright issue of the digital publishing industry.

\section{Research on Development Strategy of Digital Publishing Industry}

\subsection{Exploration of digital publishing mode}

In view of the current development trend, the digital publishing model gradually shows a diversified development. From the aspect of digital publishing, the digital publishing model is more prominent in higher education presses. They mainly convert paper content into electronic content. Based on Internet, they disseminate publications through relevant channels. And resources can be shared so that digital publishing can provide readers with a lot of convenience. Integration and accumulation of resources is an important issue in the development of digital publishing. In the contemporary development, more advanced digital technology combined with Internet technology can share and disseminate corresponding information resources. Therefore, the adoption of big data technology is very beneficial to the digital publishing industry. The application and integration of massive information resources through the technology of massive data can effectively promote the development of the digital publishing industry in its field ${ }^{[2]}$.

\subsection{Development strategy of digital publishing model}

The digital publication must transform the ideas of development in a timely manner, and must update the advance mechanism in a timely manner. The progress of the digital publishing industry not only depends on its own efforts and capabilities, but also a key factor is that it can have strong support and guidance from government departments. The existence of this factor is of great importance. The scope of digital publishing industry itself is included. Extensively, in the process of real development, we must continue to transform our thinking about the development of our society according to the actual conditions of social development, and we must timely improve and update its management mechanism. At the same time, we must also constantly The renewal of relevant policies is focused on providing protection for the development of the digital publishing industry from government policies, so as to better optimize the development of the digital publishing industry. Moreover, the adoption of new technologies is very necessary for the development of the digital publishing industry. , can greatly improve the overall level of China's digital publishing industry progress.

It is important to take the high value of the digital publishing industry, and continue to improve the digital publishing industry. In China, the development of digital publishing industry is relatively late. The development of the industrial chain has not been fully improved. Therefore, the digital publishing industry must pay attention to the improvement of the industrial chain for its own development, especially the digital publishing industry. Copyright protection should be highly valued. In the publishing process, we must pay attention to the development of content and complementary technology. The effective combination of the two must be effective. 
Increase capital investment. In the process of development, the digital publishing industry needs adequate financial support, and the government must pay attention to capital investment. Only when there is enough money can digital publishing be fully promoted in its own innovation. The key to the development of digital publishing industry lies in the updating of technology. This requires a large amount of funds to support the application of digital technology, and related technologies can run smoothly. This can ensure that the digital publishing industry's ability to independently innovate can be fully enhanced and effectively developed [3]. With the continuous introduction of modern science and technology, the digital publishing industry needs to focus attention on the use and research of two-dimensional code technology, so that the digital publishing industry in China can be effectively developed and can be promoted internationally. Competitiveness.

In the development of digital publishing industry, it is necessary to improve its industrial chain effectively and strengthen the protection of copyright step by step. At the same time, we must choose a talent system that is suitable for the development of China's digital publishing industry to integrate it effectively. Actively create conditions for common development, so that China's digital publishing industry can develop healthily. As mentioned above, China's digital publishing industry started late and has a relatively short development time. There are still areas where the industry is not really understood and implemented. Therefore, it is necessary for the digital industry to study and learn. Based on the actual situation of the development of digital industry in China, it is a combination of the development of digital publishing industry experience abroad, to compensate for your weaknesses in the development of the industry, to explore a suitable for the development of the digital publishing industry in China. On the development of China's digital publishing industry.

\section{Conclusion}

In a word, under the development trend of modern society, digital publishing industry has a very wide development space. Therefore, it is necessary to formulate relevant, scientific and reasonable data in combination with the application of big data technology and the actual progress of digital publishing industry. Advanced planning and planning can make the digital publishing industry develop well.

\section{References}

[1] Cao Yu. Research on Cooperative Development of Copyright Insurance System and Digital Publishing Industry [J]. China Publishing, 2017, (20): 67-70.

[2] Wu Yi. From a win-win situation to a symbiosis: a paradigm shift in the development of digital publishing industry clusters [J]. Publishing, 2013, (19): 31-33.

[3] Dong Ziming. Policy Traction, Innovation Drive, Structural Optimization - System Construction of China's Digital Publishing Industry Development since the Eighteenth National Congress of the Communist Party of China [J]. China Publishing, 2017, (17): 11-15.

[4] Zhao Jing. The development trend of the digital publishing industry in the context of cultural and technological integration [J]. Talented Intelligence, 2017, (27): 279. 